\title{
HER inhibitor promotes BRAF/MEK inhibitor-induced redifferentiation in papillary thyroid cancer harboring BRAFV60E
}

\author{
Lingxiao Cheng ${ }^{1, *}$, Yuchen Jin ${ }^{1, *}$, Min Liu ${ }^{1}$, Maomei Ruan ${ }^{2}$, Libo Chen ${ }^{1}$ \\ ${ }^{1}$ Department of Nuclear Medicine, Shanghai Jiao Tong University Affiliated Sixth People's Hospital, Shanghai 200233, China \\ ${ }^{2}$ Department of Nuclear Medicine, Shanghai Chest Hospital, Shanghai Jiao Tong University, Shanghai 200030, China \\ *Co-first authors
}

Correspondence to: Libo Chen, email: libochen888@hotmail.com

Keywords: papillary thyroid cancer, redifferentiation, iodine, glucose, dabrafenib

Received: October 20, $2016 \quad$ Accepted: January 24, $2017 \quad$ Published: February 28, 2017

\section{ABSTRACT}

Redifferentiation therapy with BRAF/MEK inhibitors to facilitate treatment with radioiodine represents a good choice for radioiodine-refractory differentiated thyroid carcinoma, but recent initial clinical outcomes were modest. MAPK rebound caused by BRAF/MEK inhibitors-induced activation of HER2/HER3 is a resistance mechanism, and combination with HER inhibitor to prevent MAPK rebound may sensitize BRAF ${ }^{\mathrm{V} 600 E_{-}}$ mutant thyroid cancer cells to redifferentiation therapy. To evaluate if inhibiting both BRAF/MEK and HER can produce stronger redifferetiation effect, we tested the effects of BRAF/MEK inhibitor dabrafenib/selumetinib alone or in combination with HER inhibitor lapatinib on the expression and function of iodine- and glucose-handling genes in BRAF ${ }^{\mathrm{V} 600}$-positive BCPAP and K1 cells, using BHP 2-7 cells harboring RET/ PTC1 rearrangement as control. Herein, we showed that lapatinib prevented MAPK rebound and sensitized BRAFV600E-positive papillary thyroid cancer cells to BRAF/ MEK inhibitors. Dabrafenib/selumetinib alone increased iodine-uptake and toxicity and suppressed glucose-metablism in BRAF ${ }^{\mathrm{V} 600 \mathrm{E}}$-positive papillary thyroid cancer cells. When lapatinib was added, more significant effects on iodine- and glucosehandling gene expression, cell membrane location of sodium/iodine symporter as well as radioiodine uptake and toxicity were observed. Thus, combined therapy using HER inhibitor and BRAF/MEK inhibitor presented more significant redifferentiation effect on papillary thyroid cancer cells harboring BRAF ${ }^{\mathrm{V} 600}$ than BRAF/MEK inhibitor alone. In vivo and clinical studies assessing such combined targeted redifferentiation strategy were warranted.

\section{INTRODUCTION}

Thyroid cancer is the most common endocrine malignancy with an increasing incidence over the past few decades, with differentiated thyroid carcinoma (DTC) occurring in more than $90 \%$ of cases [1]. For most cases of DTC, disease courses are indolent and cures are usually achieved with standard therapy including surgery, radioiodine $\left({ }^{131} \mathrm{I}\right)$ treatment and TSH suppression. Unfortunately, in nearly $5 \%$ of DTC patients, tumors go through a dedifferentiation process, accompanied by the silencing of iodine handling genes such as sodium/iodine symporter (NIS), TSH receptor (TSHR), thyroperoxidase (TPO), and thyroglobulin (Tg), which ultimately causes reducing of ${ }^{131} \mathrm{I}$ uptake and failure of ${ }^{131} \mathrm{I}$ treatment $[2,3]$. These radioiodine-refractory differentiated thyroid carcinoma (RR-DTC) are usually aggressive with unresectable metastatic lesions, which becomes the main cause of thyroid cancer-related morbidity and mortality [2].

Patients with RR-DTC usually show positive FDGavid lesions on ${ }^{18} \mathrm{FDG}-\mathrm{PET} / \mathrm{CT}$ due to intense glucose metabolism [4], which is partially due to the enhanced expression level of GLUT1 gene in less differentiated thyroid carcinomas [3, 5]. Decreases of GLUT1 expression have been previously detected by our group when reinducing thyroid cancer iodine-uptake with multikinase inhibitors, sorafenib/cabozantinib, which also target the MAPK pathway [6]. 
Radioiodine-refractory and iodine-handling gene silencing in thyroid cancer is associated with aberrant activating of MAPK pathway, which is frequently caused by the $B R A F^{\mathrm{V} 600 \mathrm{E}}$ mutation [4]. This has already been overcome on levels of cell lines and animal models by treatment with various kinds of BRAF and MEK inhibitors [6-8]. Furthermore, in clinical trials, blockade of MAPK pathway with the MEK inhibitor, selumetinib, and BRAF inhibitor, dabrafenib, has been demonstrated to cause redifferentiation and enhancement of radioiodine uptake in RR-DTC [9, 10]. On the basis of previous results, two randomized, placebo-controlled trials have been initiated to determine whether selumetinib followed by ${ }^{131} \mathrm{I}$ therapy prevents disease recurrence following initial surgery in patients with high-risk DTC (NCT01843062), and/or enhances tumor regression in patients with ${ }^{131} \mathrm{I}$-avid metastatic DTC (NCT02393690) [11]. However, existing results showed that only part of patients with $B R A F^{\mathrm{V} 600 \mathrm{E}}$-mutant disease developed new uptake with MEK or BRAF inhibition, and even fewer had an increased uptake that exceeded the dosimetry threshold for radioiodine treatment $[9,10]$.

Why MEK/BRAF inhibitors failed to meet high expectation in clinical trials of redifferentiation is not clear. Feedback mechanism that limits the effects of RAF/MEK inhibitors on downstream signaling in thyroid cancer may be a proper explanation for drug resistance in such redifferentiation therapy. Recent studies implicate that feedback-reactivated HER signaling causes activation of the PI3K/AKT, MEK/MAPK, and JAK/STAT signaling pathways as well as Src kinase, which ultimately causes treatment failure [12-14]. As is demonstrated in Fagin's study, thyroid tumor cells harboring the $B R A F^{\mathrm{V} 600 \mathrm{E}}$ over express HER signaling pathway when treated with BRAF/ MEK inhibitors, reactivating ERK and/or AKT [15]. Combination of HER inhibitor to BRAF/MEK inhibitor solves the problem of drug resistance [15]. Therefore, we hypothesize that greater redifferetiation effect may be achieved via dual inhibition of BRAF/MEK and HER than sole inhibition of BRAF/MEK.

In the present study, we investigate whether simultaneous inhibition of BRAF/MEK with dabrafenib/ selumetinib and HER with lapatinib has stronger redifferetiation effect and lead to greater augment in radioiodine uptake than sole inhibition of BRAF/MEK. Meanwhile, we observe whether GLUT expression and FDG uptake can be suppressed to a lower extent after simultaneous inhibition, in order to judge the potential of ${ }^{18} \mathrm{~F}$-FDG PET in revealing efficacy of redifferentiation therapy.

\section{RESULTS}

\section{Gene sequencing}

Mutant $B R A F^{\mathrm{v} 600 \mathrm{E}}$ and wild-type $N R A S$ genes were confirmed in BCPAP cells. Mutant $B R A F^{\mathrm{V} 600 \mathrm{E}}$, $P I K 3 C A$ and wild-type NRAS gene were confirmed in
K1 cells. RET/PTC1 rearrangement with wild-type genes of BRAF and NRAS were confirmed in BHP 2-7 cells. Genetic alterations of these cell lines are presented in Supplementary Figure 1.

\section{Effects on cell proliferation and cell cycle}

As is shown in Supplementary Figure 2, the half maximal inhibitory concentration $\left(\mathrm{IC}_{50}\right)$ of dabrafenib in BCPAP cells, K1 cells and BHP 2-7 cells were $232 \mathrm{nM}$, $146 \mathrm{nM}, 315 \mathrm{nM}$, respectively. And the $\mathrm{IC}_{50}$ of selumetinib in BCPAP cells, K1 cells and BHP 2-7 cells were 9274 $\mathrm{nM}, 16270 \mathrm{nM}, 23370 \mathrm{nM}$, respectively. $\mathrm{IC}_{50}$ of lapatinib in the three cell lines were $9134 \mathrm{nM}, 11330 \mathrm{nM}$ and $4250 \mathrm{nM}$, respectively. Lapatinib markedly sensitized the three cell lines to dose-dependent inhibition by the BRAF/MEK inhibitor. When $1 \mu \mathrm{M}$ lapatinib was added to BCPAP cells, $\mathrm{K} 1$ cells and BHP 2-7 cells, the $\mathrm{IC}_{50}$ of dabrafenib decreased significantly to $74 \mathrm{nM}, 47 \mathrm{nM}$ and $201 \mathrm{nM}$, respectively, and the $\mathrm{IC}_{50}$ of selumetinib dropped significantly to $2395 \mathrm{nM}, 1320 \mathrm{nM}$ and $8563 \mathrm{nM}$, respectively.

We had set a Concentration gradients in preexperiments were set and dabrafenib at $0.1 \mu \mathrm{M}$, selumetinib at $2.5 \mu \mathrm{M}$ and lapatinib at $1 \mu \mathrm{M}$ were found to induced preferable redifferentiation effect in BCPAP and K1 cells. Such concentrations were used in the following experiments.

When treated with DMSO, $46 \%$ of the BCPAP cells were found to be in the $\mathrm{G} 1$ phase, $38.7 \%$ in the $\mathrm{S}$ phase, and $14.9 \%$ in the $\mathrm{G} 2$ phase; $67.5 \%$ of the $\mathrm{K} 1$ cells were found to be in the G1 phase, $27.9 \%$ in the $\mathrm{S}$ phase, and $5.6 \%$ in the G2 phase; $55.0 \%$ of the BHP $2-7$ cells were found to be in the G1 phase, $30.7 \%$ in the $\mathrm{S}$ phase, and $14.3 \%$ in the G2 phase. BCPAP cells and K1 cells treated with $0.1 \mu \mathrm{M}$ dabrafenib alone or in combination with 1 $\mu \mathrm{M}$ lapatinib for $24 \mathrm{~h}$ significantly differ in $\mathrm{G} 1 / \mathrm{S}$ phase content compared with the DMSO control $(P<0.01)$ (Supplementary Figure 3). When treated with $2.5 \mu \mathrm{M}$ selumetinib alone or in combination with $1 \mu \mathrm{M}$ lapatinib, BCPAP cells and K1 cells were arrested in the G1 phase with statistical significance $(P<0.01)$ compared with the amount of cells in the G1/S phase in the DMSO control (Supplementary Figure 3). Neither BRAF/MEK inhibition nor dual inhibition of BRAF/MEK and HER induced marked cell cycle arrest in the G1 phase in BHP 2-7 cells (Supplementary Figure 3).

\section{Prevention of MAPK rebound induced by BRAF/MEK inhibitor}

As shown in Figure 1A, the inhibitory effect of dabrafenib on MAPK signaling pathway in $B R A F$-mutant BCPAP cells was transient, with a MAPK rebound beginning nearly $8 \mathrm{~h}$ after addition of dabrafenib. The expression of the HER2 and HER3 increased after $6 \mathrm{~h}$ 
incubation with dabrafenib, which was accompanied by elevated AKT phosphorylation activity. Lapatinib blocked the superactivated HER2/HER3, AKT and pERK1/2 induced by dabrafenib. In BRAF-mutant $\mathrm{K} 1$ cells, HER3 activating and pERK1/2 rebound was also induced with dabrafenib treatment, which was blocked by lapatinib (Supplementary Figure 4).

When the BCPAP cells were incubated with selumetinib, activation of HER and rebound of pERK1/2 was observed and this was prevented via co-incubating with lapatinib (Figure 1B).

\section{Effect on the expression of iodine- and glucose- handling genes}

For BCPAP cells and K1 cells, treatment with dabrafenib or selumetinib for 48 hours increased the mRNA levels of iodine-handling genes, including NIS, $\mathrm{Tg}$, TPO, and TSHR (Figure 2). The mRNA levels of
GLUT1 reduced, but the mRNA levels of GLUT3 were not significantly changed (Figure 2). In BHP 2-7 cells, this effect was generally modest (Figure 2). Combination of MAPK inhibitor and HER inhibitor lapatinib induced a more robust expression of iodine-handling genes in BCPAP cells and K1 cells while mRNA level of GLUT1 was reduced to a lower extent (Figure 2).

Western blot analysis demonstrated that dabrafenib restored the expression of NIS, Tg, TSHR, and TPO, and reduced the expression of GLUT1 (Figure 3) in both BCPAP and K1 cells. More evident effect was observed with dual inhibition of MAPK and HER. For BHP 2-7 cells, however, no significant changes in the expression of glucose and iodine-handling genes were observed (Supplementary Figure 5).

NIS protein expression was illustrated by immunofluorescent microscopy. While there was virtually no basal NIS protein expression, NIS staining in the peripheral areas of the cell was notable in BCPAP
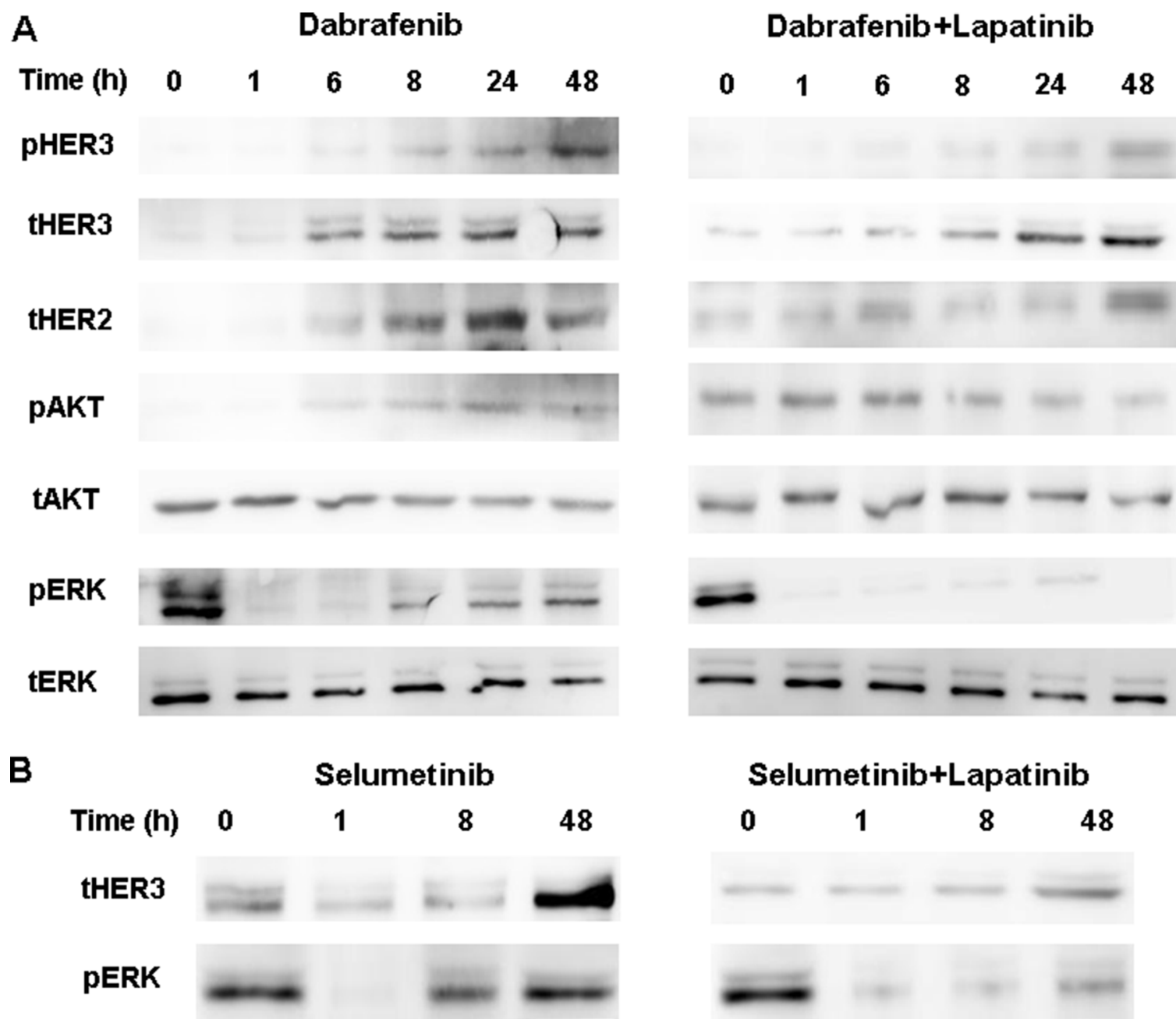

Figure 1: (A) Western blot of lysates of BCPAP cells treated with $0.1 \mu \mathrm{M}$ dabrafenib with or without $1 \mu \mathrm{M}$ lapatinib for indicated times. Lapatinib blocked the dabrafenib-induced HER3 and AKT phosphorylation and the pERK1/2 rebound. (B) BCPAP cells were treated with $2.5 \mu \mathrm{M}$ selumetib with or without $1 \mu \mathrm{M}$ lapatinib and collected at $0,1,8$, and $48 \mathrm{~h}$ post-treatment. Lysates were Western blotted for HER3 and ERK. 
cells (Figure 4) and K1 cells (Supplementary Figure 6) when treated with dabrafenib or selumetinib, suggesting increased cell membrane localization. NIS was more clearly localized in the peripheral areas of the cell under combined treatment with dabrafenib/selumetinib and lapatinib.

\section{Radioiodine uptake and efflux assay}

As shown in Figure 5, radioiodine uptake was 1.72fold higher $(P<0.01)$ in BCPAP cells and 1.64-fold higher $(P<0.05)$ in $\mathrm{K} 1$ cells when incubated with dabrafenib compared with nontreated cells. Combined treatment with dabrafenib and lapatinib induced 3.20-fold higher $(P<$ $0.01)$ and 3.73 -fold higher $(P<0.01)$ radioiodine uptake in BCPAP cells and K1 cells respectively. When treated with selumetinib, radioiodine uptake was 1.72 -fold higher $(P<0.01)$ in BCPAP cells and 2.69-fold higher $(P<0.01)$ in $\mathrm{K} 1$ cells compared with nontreated cells. Combination of selumetinib and lapatinib induced 3.55-fold higher $(P<0.01)$ and 4.04 -fold higher $(P<0.01)$ radioiodine uptake in the two cell lines respectively. Iodine uptake was specifically dependent on NIS because it was blocked by $\mathrm{NaClO}_{4}$. Radioiodine uptake of BHP 2-7 cells increased when using combined treatment with dabrafenib and lapatinib $(P=0.022)$, while did not increased with other treatment.

We also evaluate the ability of BCPAP cells and $\mathrm{K} 1$ cells to retain iodine under single-drug or combined treatment (Supplementary Figure 7). There was a rapid efflux of radioactivity from the non-treated BCPAP and K1 cells $\left(\mathrm{t}_{1 / 2}=6.74 \mathrm{~min}\right.$ and $\mathrm{t}_{1 / 2}=6.22 \mathrm{~min}$ respectively $)$, iodine retention was not significantly prolonged in the dabrafenib treated group $\left(\mathrm{t}_{1 / 2}=8.53 \mathrm{~min}\right.$ in BCPAP cells and $\mathrm{t}_{1 / 2}=7.09$ min in K1 cells, $P=0.194$ and $P=0.118$, respectively) or in selumetinib treated group $\left(\mathrm{t}_{1 / 2}=8.20 \mathrm{~min}\right.$ in BCPAP cells and $\mathrm{t}_{1 / 2}=7.66 \mathrm{~min}$ in $\mathrm{K} 1$ cells, $P=0.108$ and $P=0.149$, respectively). Nor was retention time prolonged in combined treatment groups $\left(\mathrm{t}_{1 / 2}=9.00 \mathrm{~min}\right.$ in BCPAP cells and $\mathrm{t}_{1 / 2}=$ $8.57 \mathrm{~min}$ in $\mathrm{K} 1$ cells, $P=0.083$ and $P=0.057$, respectively in dabrafenib \& lapatinib group and $\mathrm{t}_{1 / 2}=9.09 \mathrm{~min}$ in BCPAP cells and $\mathrm{t}_{1 / 2}=7.75 \mathrm{~min}$ in $\mathrm{K} 1$ cells, $P=0.065$ and $P=0.332$, respectively in selumetinib \& lapatinib group).

\section{In vitro clonogenic assay}

In ${ }^{131}$ I treated BCPAP cells and $\mathrm{K} 1$ cells, compared to DMSO treated controls, the numbers of colonies were significantly smaller in dabrafenib treated groups ( $P=0.034$ for BCPAP cells and $P=0.009$ for K1 cells) and dabrafenib \& lapatinib treated groups $(P=0.006$ for BCPAP cells and $P=0.000$ for K1 cells). Further, the numbers of colonies were significantly smaller in dabrafenib \& lapatinib treated groups compared to that in dabrafenib treated groups $(P=0.005$ for BCPAP cells and $P=0.006$ for K1 cells) (Figure 6).

In ${ }^{131} \mathrm{I}$ treated BCPAP cells and $\mathrm{K} 1$ cells, compared to DMSO treated controls, the numbers of colonies

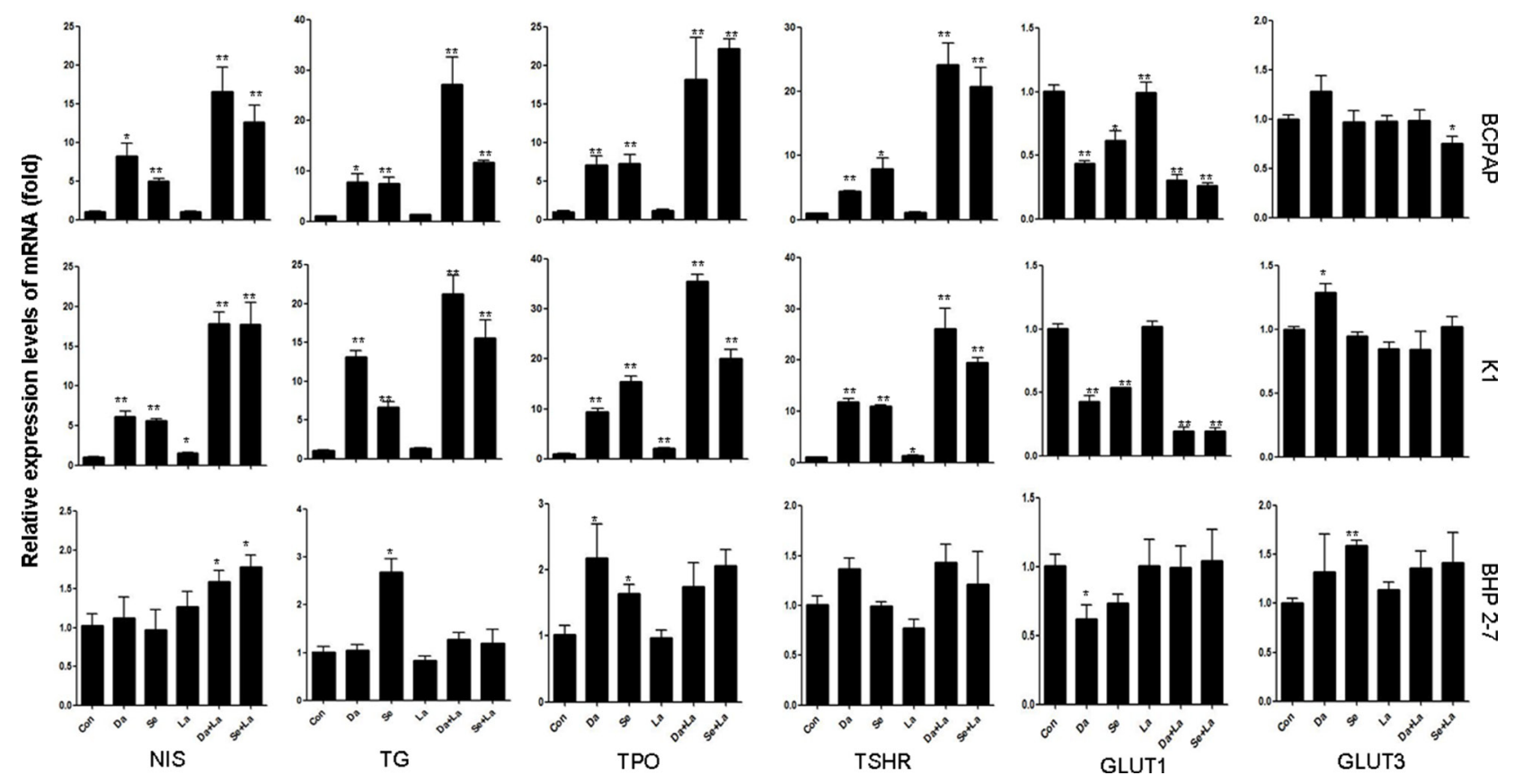

Figure 2: Effects of different treatment on the mRNA levels of sodium iodine symporter (NIS), thyroglobulin (Tg), thyroid peroxidase (TPO), thyroid-stimulating hormone receptor (TSHR); and on glucose transporter isoforms (GLUT1 and GLUT3) genes in BCPAP cells, K1 cells and BHP 2-7 cells. Cells were treated with $0.1 \mu \mathrm{M}$ dabrafenib/2.5 $\mu \mathrm{M}$ selumetinib and $1 \mu \mathrm{M}$ lapatinib alone or in combination. Data are presented as means $\pm \mathrm{SD} . * P<0.05$; $* * P<0.01$ for comparison with control. Con: control (DMSO); Da: dabrafenib; Se: selumetinib; La: lapatinib. 
decreased significantly in dabrafenib treated groups ( $P$ $=0.005$ for BCPAP cells and $P=0.013$ for $\mathrm{K} 1$ cells) and dabrafenib \& lapatinib treated groups $(P=0.001$ for BCPAP cells and $P=0.001$ for K1 cells). Further, dabrafenib combined with lapatinib induced a significant reduction in the numbers of colonies compared to that in dabrafenib treated groups $(P=0.007$ for BCPAP cells and $P=0.017$ for K1 cells) (Figure 6).

\section{DISCUSSION}

Silencing of NIS, along with other iodine-handling genes results in resistance to radioiodine treatment, which is associated with activation of MAPK pathway [4]. Recent progresses in both preclinical and clinical study have provided promises for blockading the MAPK pathway to restore radioiodine avidity [6-10]. In our previous study, sorafenib and carbozatinib have been demonstrated to blockade the MAPK pathway and increase radioiodine uptake in PTC cells [6]. However, multikinase inhibitors have worse patient tolerability than BRAF/MEK inhibitors [16-18], so redifferentiation therapy with these BRAF/MEK inhibitors to facilitate treatment with radioiodine represents a better choice for patients with RR-DTC. Unfortunately, in clinical trials with small sample size, rediffereniation therapy with MEK or BRAF inhibitors failed to meet high expectation $[9,10]$. Novel strategies to augment the effect of BRAF/MEK inhibitor-induced redifferentiation are urgently needed.

Recently, much work has been done on exploring mechanisms of resistance to BRAF inhibitors in various cancers including thyroid cancer $[12-14,16]$. Fagin and colleagues reported that BRAF/MEK inhibitor treated thyroid cells showed HER activating, thereby increasing the activation of both the MAPK and PI3K pathways. It was further demonstrated that combination with

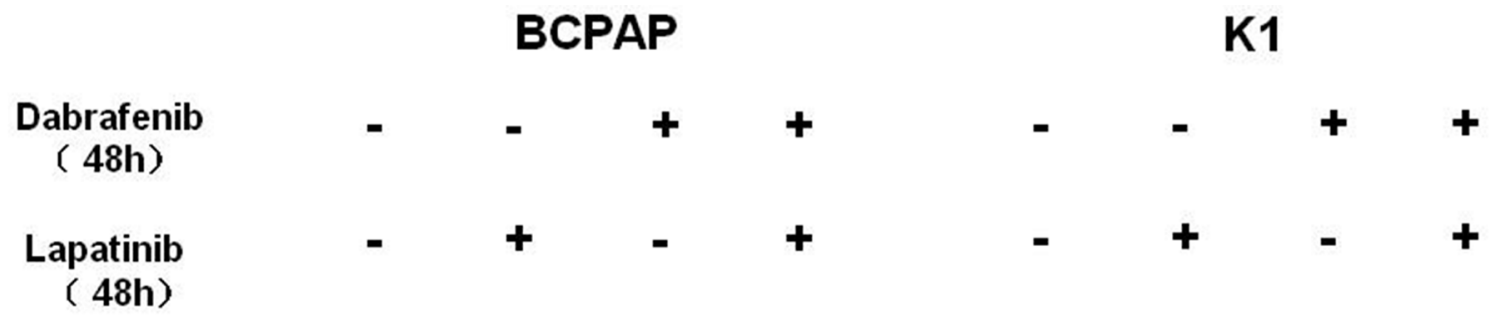

NIS
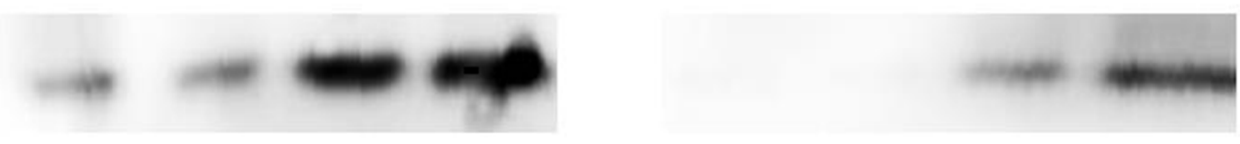

TG
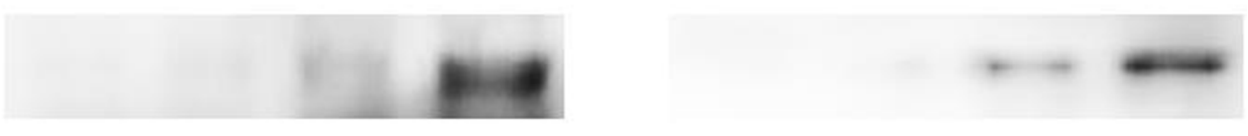

TPO

TSHR
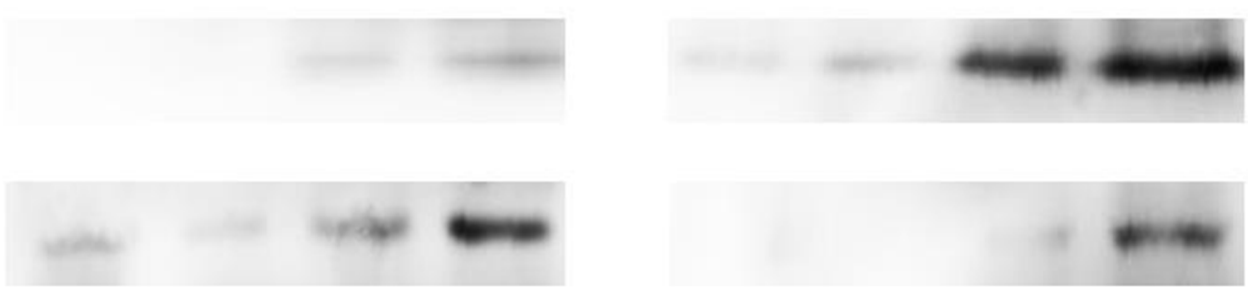

GLUT1
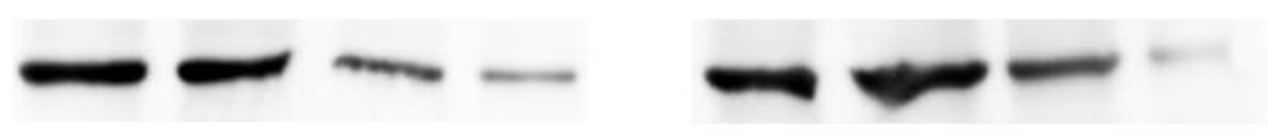

$\beta$-actin
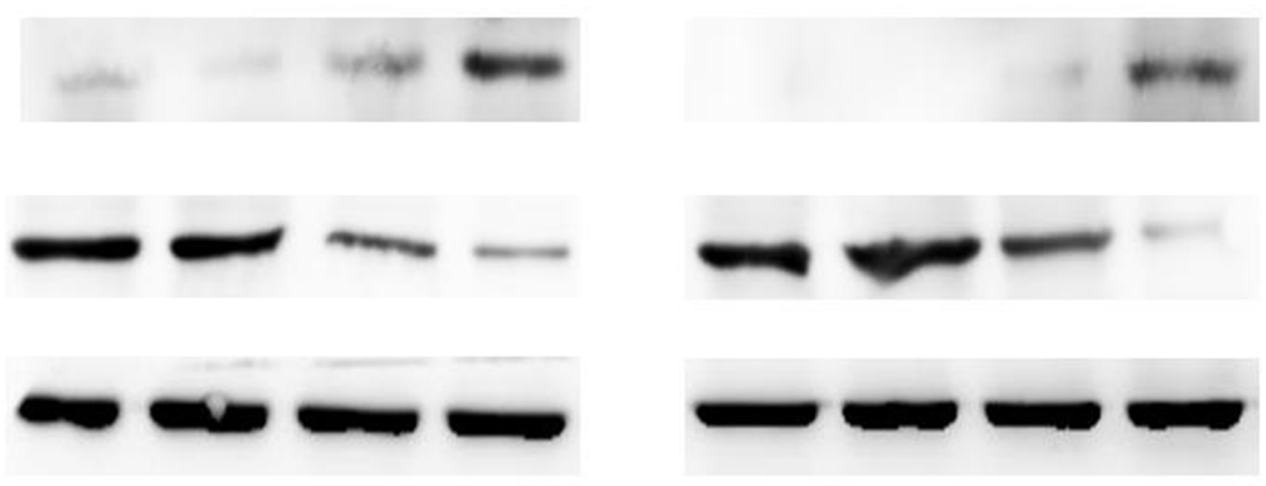

Figure 3: Western blot demonstrating the effects of different treatment on the protein levels of sodium iodine symporter (NIS), thyroglobulin (Tg), thyroid-stimulating hormone receptor (TSHR), thyroid peroxidase (TPO), glucose transporter-1 (GLUT1) in BCPAP (left) and K1 (right) cells. Cells were treated with $0.1 \mu \mathrm{M}$ dabrafenib alone or in combination with $1 \mu \mathrm{M}$ lapatinib. $\beta$-actin was used as positive control. 
HER inhibitor lapatinib prevented MAPK rebound and sensitized $B R A F$-mutant thyroid cancer cells to BRAF or MEK inhibitors [15]. This study provides a rationale for combining ERK pathway antagonists with inhibitors of feedback reactivated HER signaling in thyroid cancer, yielding a sustained and enhanced redifferentiation effect.

In the present study, we utilized in vitro model to evaluate the efficacy of dabrafenib /selumetinib in combination with lapatinib, a drug with acceptable adverse effect profiles in patients with breast and head/neck cancer
[19], as a potential combined redifferentiation therapeutic strategy. Using such combination strategy in $B R A F^{\mathrm{V} 600 \mathrm{E}_{-}}$ positive PTC cells, the expression of iodine-handling genes in thyroid cancer cells increased to a greater extent, localization of NIS to the cell membrane was greater promoted, and radioiodine uptake and toxicity were augmented to a higher level. In line with prior study using vemurafenib and lapatinib [15], MAPK rebound and PI3K pathway activation after dabrafenib/selumetinib treatment was detected in a time dependent manner, and addition of

\section{Lapatinib -}

\section{DMSO}
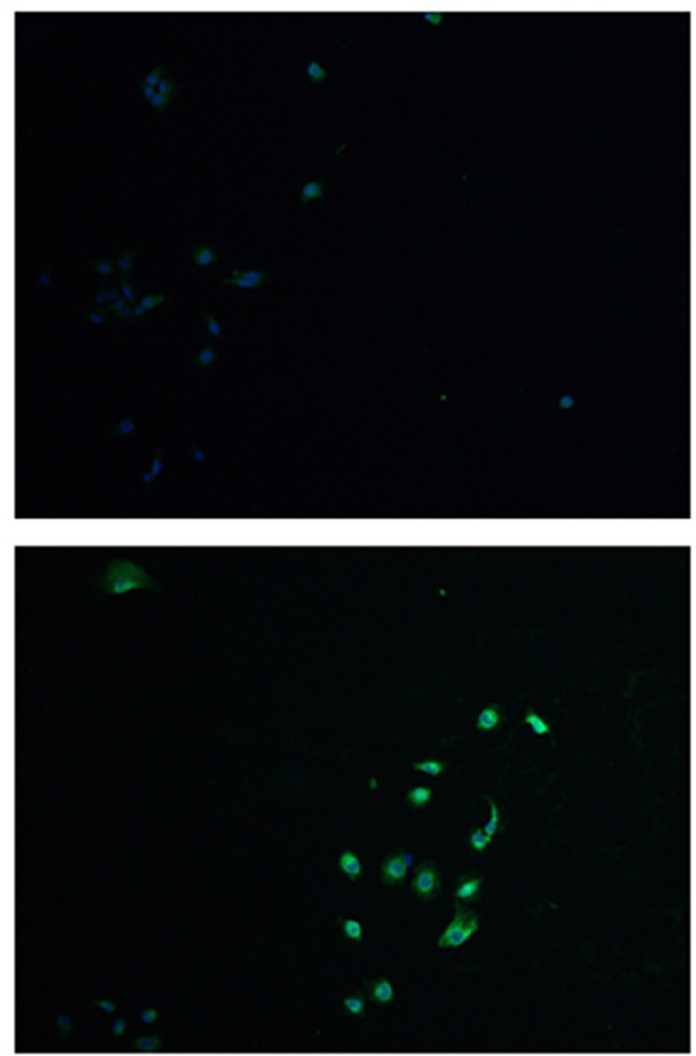

$\mathrm{Da}$

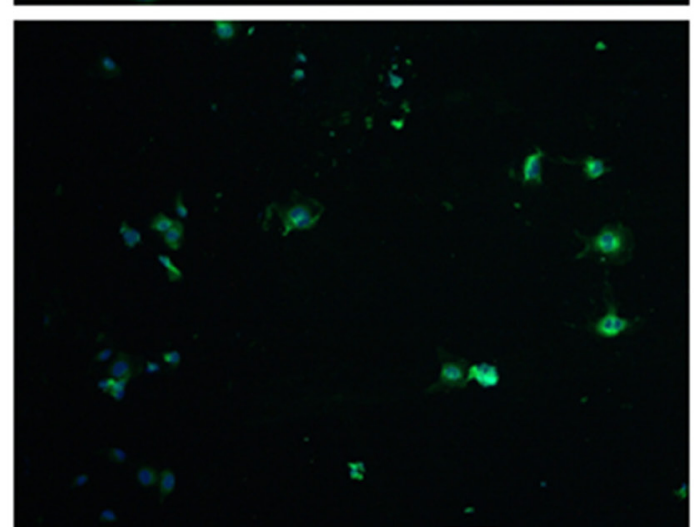

\section{Lapatinib +}
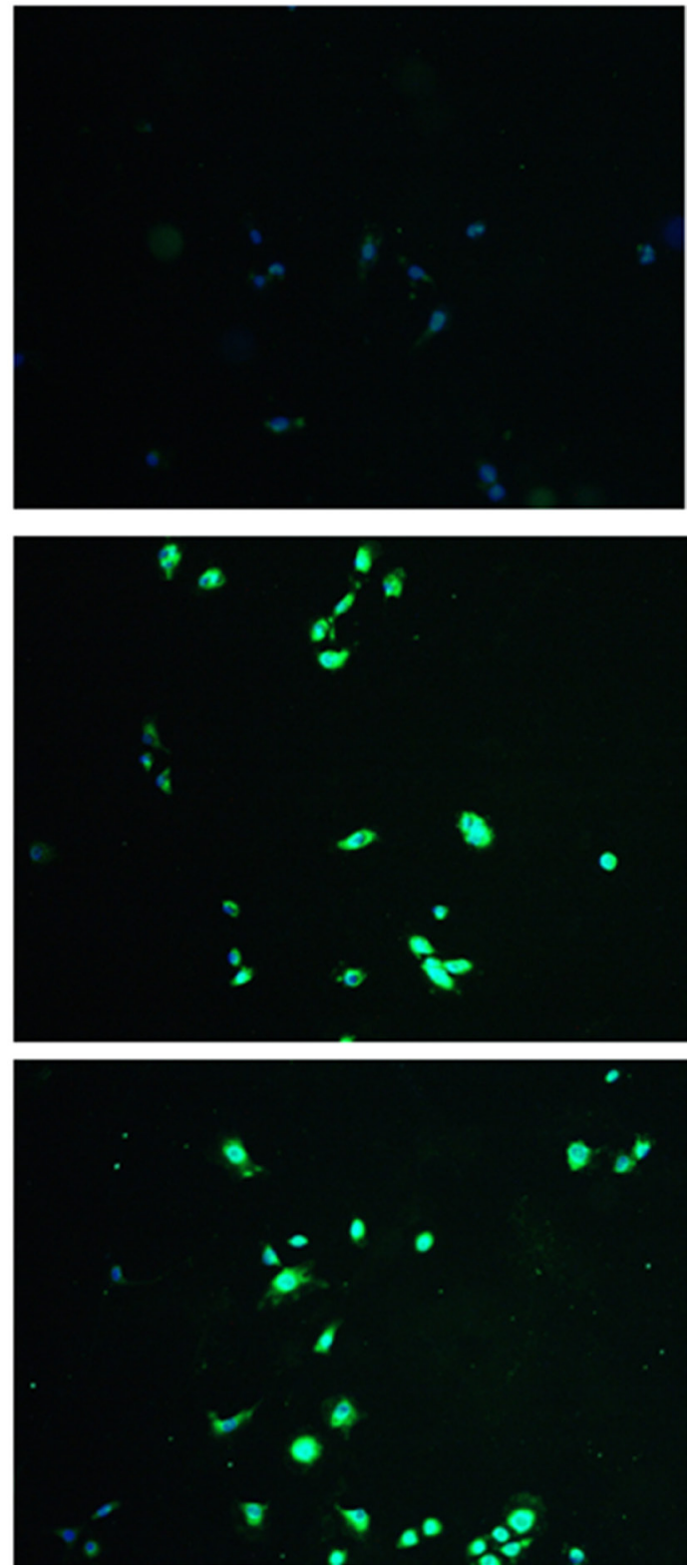

Figure 4: Immunofluorescent microscopic analysis of NIS protein expression in BCPAP cells. Cells were treated with 0.1 $\mu \mathrm{M}$ dabrafenib/2.5 $\mu \mathrm{M}$ selumetinib and $1 \mu \mathrm{M}$ lapatinib alone or in combination. Double immunofluorescent microscopy was displayed with the blue color representing DAPI nuclear staining and the green color representing NIS staining. NIS staining was negative in the nontreated and lapatinib treated cells. In cells treated with dabrafenib/selumetinib, NIS staining was notable. The most robust expression of NIS was seen in the combined treatment groups. Da: dabrafenib; Se: selumetinib. 

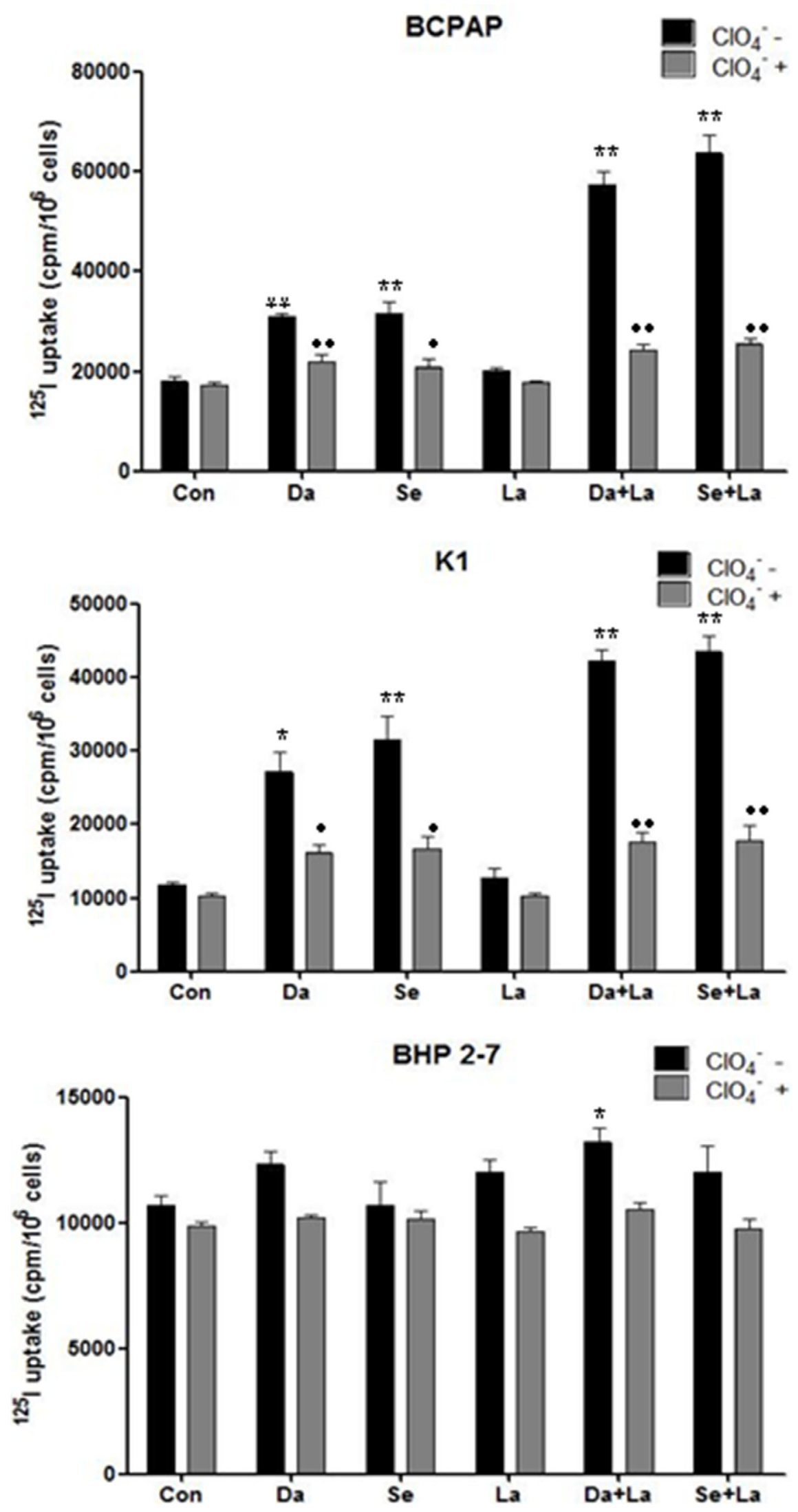

Figure 5: Radioactive iodine uptake in BCPAP cells, K1 cells, and BHP 2-7 cells. Cells were treated with $0.1 \mu \mathrm{M}$ dabrafenib/ $2.5 \mu \mathrm{M}$ selumetinib and $1 \mu \mathrm{M}$ lapatinib alone or in combination. Data are expressed as mean $\pm \mathrm{SD}$ of values. ${ }^{*} P<0.05,{ }^{* *} P<0.01$ compared with untreated cells. ${ }^{\bullet} P<0.05, \bullet P<0.01$ compared with $\mathrm{NaClO}_{4}$ treated cells. Da: dabrafenib; Se: selumetinib; La: lapatinib. 
lapatinib to the BRAF/MEK inhibitor prevented activation of MAPK and PI3K pathways, which may be the mechanism underlying this combined redifferentiation effect. Our data suggest that combined therapy using HER inhibitor and BRAF/MEK inhibitor can produce more significant redifferentiating effect on thyroid cancer cells than single drug treatment with BRAF/MEK inhibitor alone, since MAPK rebound during BRAF/MEK inhibitor treatment can be effectively prevented. Our study provides basis for in vivo and clinical studies using combination of dabrafenib/ selumetinib and lapatinib in conjunction with ${ }^{131} \mathrm{I}$ therapy, which may become a promising therapeutic regimen for RRDTC, particularly in $B R A F^{\mathrm{V} 600 \mathrm{E}}$-positive cases.

Iodine accumulation in thyroid follicle cells involves two steps of transport, basolateral uptake and apical efflux, which are both important factors for cytotoxic effect of ${ }^{131} \mathrm{I}$
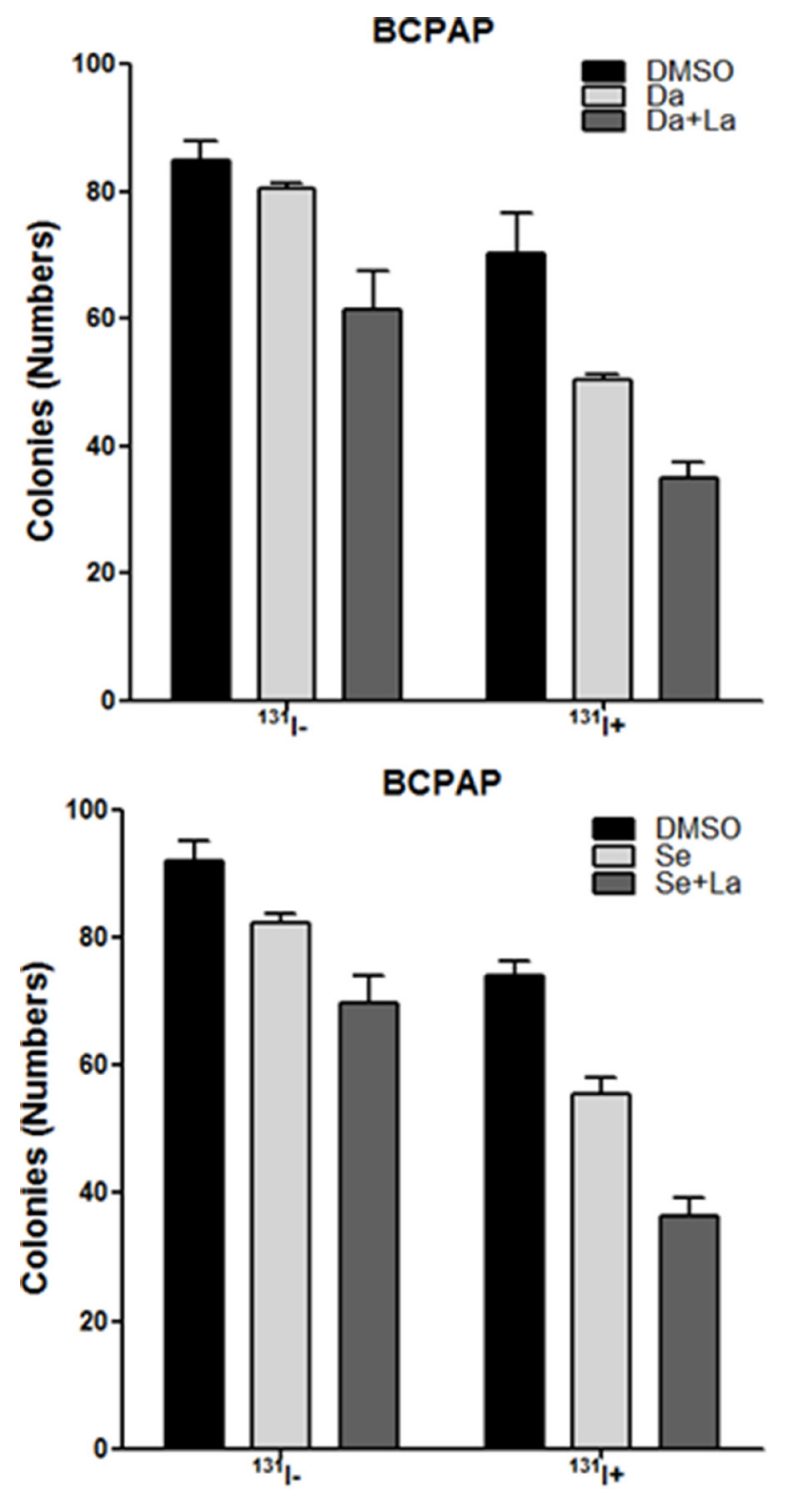

[20]. The efflux of iodine across the apical membrane is mediated by pendrin, SLC5A8, ClCn5 and Anoctamin 1, etc. Iodine efflux or retention represents a team effort by various apical membrane proteins [21-25]. Previous studies have revealed regulation mechanisms of several apical membrane iodine transporters: pendrin membrane abundance is regulated by $\mathrm{TSH}[21,26]$; silencing of SLC5A8 is secondary to the constitutive activation of the MAPK pathway [26, 27]. In our study, however, neither dabrafenib/ selumetinib treatment nor combined treatment significantly changed radioiodine retention time in thyroid cancer cells, although MAPK pathway was blocked by these treatments. It maybe due to that MAPK inhibitor alone is not sufficient to alter the activities of all the apical membrane proteins.

An inverse relationship between ${ }^{131} \mathrm{I}$ and ${ }^{18} \mathrm{~F}-\mathrm{FDG}$ uptake ("flip-flop phenomenon") was described for

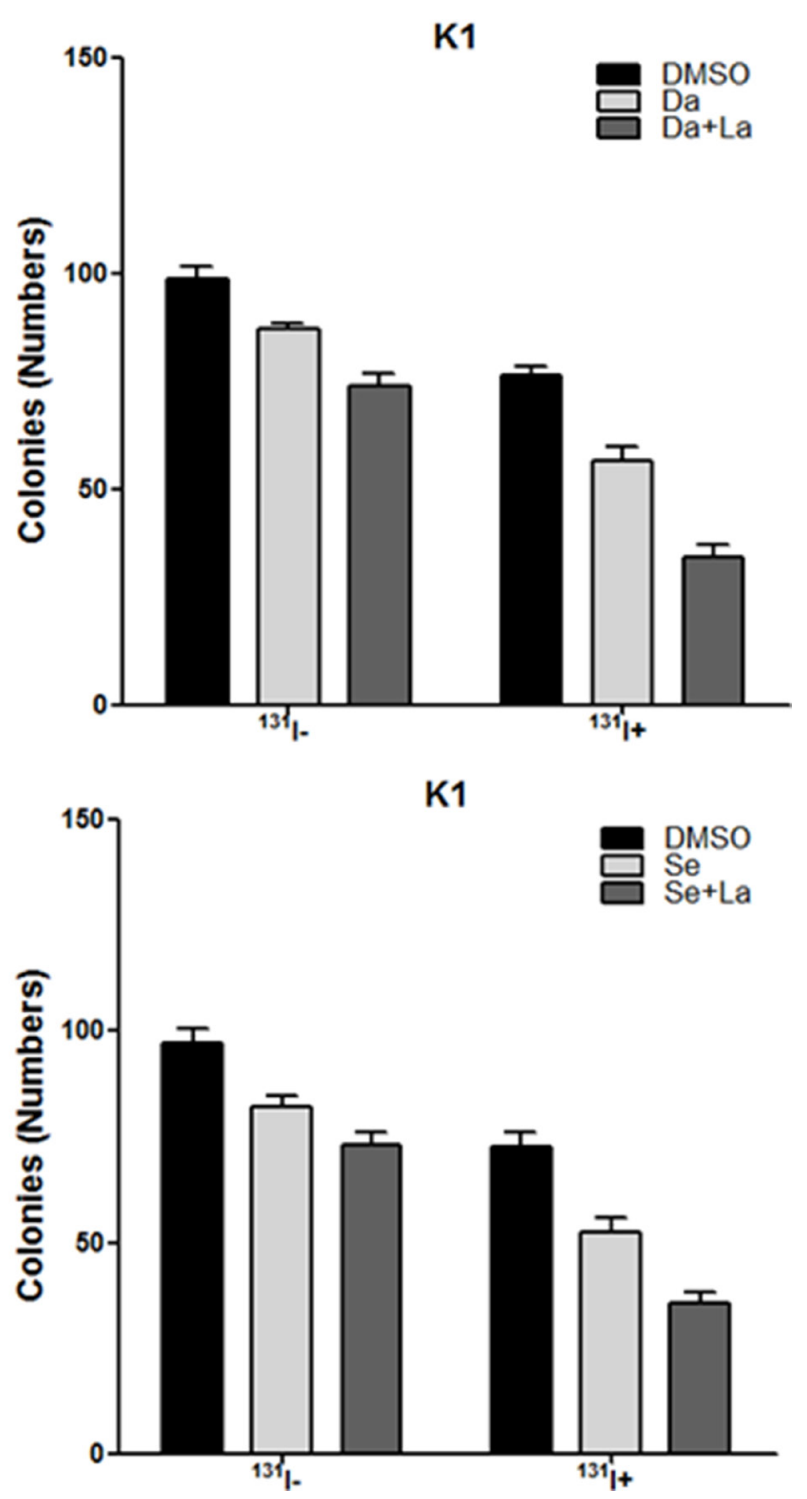

Figure 6: In vitro clonogenic assay. Data are represented as number of colonies in BCPAP cells and K1 cells treated with DMSO, $0.1 \mu \mathrm{M}$ dabrafenib/2.5 $\mu \mathrm{M}$ selumetinib alone or in combination with $1 \mu \mathrm{M}$ lapatinib with $\left({ }^{131} \mathrm{I}+\right)$ or without ${ }^{131} \mathrm{I}\left({ }^{131} \mathrm{I}-\right)$. Data are expressed as mean $\pm \mathrm{SD}$. Da: dabrafenib; Se: selumetinib; La: lapatinib. 
thyroid cancers during dedifferentiation [5]. A molecular mechanism underlying ${ }^{18} \mathrm{~F}-\mathrm{FDG}$ uptake in poorly differentiated thyroid cancers is that dedifferentiation in thyroid cancer is accompanied by GLUT1 upregulation $[3,5]$. In our previous study, the expression of GLUT1 and GLUT3 and the ${ }^{18}$ F-FDG uptake were significantly decreased in BHP 2-7 cells harboring RET/PTC rearrangement after redifferentiation therapy with either sorafenib or carbozatinib, indicating that monitoring efficacy of redifferentiation therapy using ${ }^{18} \mathrm{~F}-\mathrm{FDG}$ PET is possible [6]. The present study demonstrated that the expression levels of GLUT1 in DTC cells decreased significantly after BRAF/MEK inhibition and was even lower after dual inhibition of BRAF/MEK and HER, once again providing rationale for monitoring efficacy of redifferentiation therapy using ${ }^{18} \mathrm{~F}$-FDG PET. However, GLUT3 expression level was not significantly changed in any of the treated groups, which is different from the trend in our previous study, while this was consistent with Perrier's findings that GLUT1 is upregulated during thyroid carcinogenesis and other GLUTs were statistically unchanged [28].

Previous studies demonstrated $B R A F^{\mathrm{V} 600 \mathrm{E}}$-dependent inhibition in thyroid cancer cells by BRAF inhibitors [29, 30]. Compared to $B R A F$ wild-type BHP 2-7 cells, BRAF inhibitor dabrafenib preferentially inhibited ERK signaling and thyroid cancer cell proliferation, arrested cell circle, and regulated iodine and glucose-handling gene expression in $B R A F^{\mathrm{V} 600 \mathrm{E}}$-positive PTC cells. A possible explanation of this phenomenon is that BRAF inhibitor binding activates wild-type RAF isoforms by inducing dimerization, membrane localization and interaction with RAS-GTP, which ultimately activates the MAPK pathway [31]. It is noteworthy that although MEK inhibitor also exhibited preferentially inhibition of $B R A F^{\mathrm{V} 600 \mathrm{E}}$-positive PTC cells owing to its target just downstream of BRAF, selumetinib lacked efficacy on $B R A F$ wild-type BHP 2-7 cells for the regulation of cell proliferation, apoptosis, cell cycle and metabolism, which is probably due to persistent activating of PI3K/AKT pathway, negating its inhibitory effect on ERK signaling [32, 33].

It must be pointed out that although dabrafenib, selumetinib and lapatinib have acceptable adverse effects. In clinical use, patients receiving the combination therapy may require more dose modifications than did those receiving monotherapy. Interrupting treatment at the first sign of severe side effect is critical. To our comfort, however, previous study comparing combined BRAF and MEK inhibition to BRAF inhibition showed no significant between-group difference in the frequency of adverse events, including grade 3 and 4 toxic effects [34].

In summary, our in vitro study suggests that BRAF/ MEK inhibitor-induced redifferentiation effect in PTC cells harboring $B R A F^{\mathrm{V} 600 \mathrm{E}}$ can be promoted by HER inhibitor via effectively preventing MAPK rebound. It provides basis for in vivo and clinical studies using combination of dabrafenib/selumetinib and lapatinib in conjunction with ${ }^{131} \mathrm{I}$ therapy, which may become a potential therapeutic regimen for RR-DTC, particularly in $B R A F^{\mathrm{V} 600 \mathrm{E}}$-positive patients.

\section{MATERIALS AND METHODS}

\section{Cell culture and agents}

The K1 cell line was obtained from health protection agency culture collection, BCPAP cell line was purchased from Chinese Academy of Science. BHP 2-7 cell line was kindly provided by Prof. Jerome M. Hershman. All cell lines were maintained at $37^{\circ} \mathrm{C}$ and $5 \% \mathrm{CO}_{2}$ in humidified atmosphere and grown in RPMI 1640 growth media supplemented with 10\% fetal bovine serum (GIBCO). Under these culture conditions, cells were treated with dabrafenib, selumetinib and lapatinib (MCE) individually or in combination for indicated times. Dimetylsulfoxide (DMSO) was used in parallel as vehicle control.

\section{Oncogene analysis and cell proliferation assay}

Total RNAs were prepared from cells cultured for oncogene analysis using RNeasy kit (Qiagen). Primer sequences are displayed in Supplementary Table 1. The Cell Counting Kit-8 (DOJINDO) was used to detect cell proliferation after cells were cultured with increasing concentrations of dabrafenib, selumetinib and lapatinib alone or in combination for $24 \mathrm{~h}, 48 \mathrm{~h}$, and $72 \mathrm{~h}$. $\mathrm{IC}_{50}$ was calculated using Prism 5.0 (GraphPad Software).

\section{Cell cycle analysis}

Cells $\left(3.0 \times 10^{5}\right)$ were grown in $25 \mathrm{~cm}^{2}$ flasks overnight and incubated with dabrafenib at $0.1 \mu \mathrm{M}$, selumetinib at $2.5 \mu \mathrm{M}$ and lapatinib at $1 \mu \mathrm{M}$ individually or in combination or DMSO for $24 \mathrm{~h}$, and subsequently used for cell cycle analysis. The samples were analyzed by flow cytometry (Becton Dickinson, USA).

\section{RNA extraction and real-time quantitative RT- PCR analysis}

Cells $\left(3.0 \times 10^{5}\right)$ were seeded in $25 \mathrm{~cm}^{2}$ flasks and then incubated with dabrafenib at $0.1 \mu \mathrm{M}$, selumetinib at 2.5 $\mu \mathrm{M}$ and lapatinib at $1 \mu \mathrm{M}$ individually or in combination or DMSO for $48 \mathrm{~h}$. Total RNA was isolated from cells using RNeasy kit (Qiagen), Total RNA $(1 \mu \mathrm{g})$ was converted to cDNA on an iCycler Thermal Cycler (Bio-Rad Laboratories) using QuantiTect Reverse Transcription Kit (Qiagen). Realtime quantitative RT-PCR analysis was performed on an ABI Prism 7900HT Sequence Detector (Applied Biosystems) using SYBR Green MasterMix(Qiagen). 18S was run in parallel to standardize the input cDNA. Primer design was performed using Primer Express 2 [6]. 


\section{Western blotting assay}

Cells were lysed in RIPA buffer. Equal amounts of total protein were resolved by SDS-PAGE, transferred to PVDF membranes (Millipore), and immunoblotted with the indicated primary antibodies. Membranes were hybridized with the following primary antibodies: p-Erk1/2, Erk1/2, p-HER3/ErbB3, HER3/ErbB3, HER2/ErbB2, p-AKT, AKT (Cell Signaling Technology), NIS, Tg, TPO, TSHR, GLUT1, and GLUT3 (Protein tech). Membranes were then hybridized with species-specific HRP-conjugated antibodies. Bands were visualized with Potent ECL kit (Beyotime).

\section{Immunofluorescent localization of NIS}

Cells $\left(2.0 \times 10^{4}\right)$ were seeded in 6-well chamber slides. After $72 \mathrm{~h}$ of incubation with specific inhibitors, cells were fixed in paraformaldehyde. Cells were then incubated in succession with rabbit anti-NIS (1:100; Protein tech), Alexa Fluor 488-conjugated Goat anti-rabbit IgG secondary antibody (1:100, Thermo) and DAPI. Fluorescent microscopic examination was conducted to monitor NIS expression (Nikon Corporation, Tokyo, Japan).

\section{Iodine uptake and efflux assay}

Cells $\left(1.5 \times 10^{5}\right)$ were seeded in 6-well plates and then incubated with dabrafenib at $0.1 \mu \mathrm{M}$, selumetinib at $2.5 \mu \mathrm{M}$ and lapatinib at $1 \mu \mathrm{M}$ individually or in combination or DMSO for $48 \mathrm{~h}$. For iodine uptake assay, one well was counted for cell number for each group, and the remaining wells were incubated in $1 \mathrm{~mL}$ serum-free RPMI 1640 containing $2 \mu \mathrm{Ci} \mathrm{Na}{ }^{125}$ I. Following incubation at $37^{\circ} \mathrm{C}$ for $1 \mathrm{~h}$, the medium containing $\mathrm{Na}^{125} \mathrm{I}$ was removed and the cells were washed twice with PBS. Then the cells were lysed with $0.3 \mathrm{~mol} / \mathrm{L}$ sodium hydroxide on ice. Cell-associated radioiodine was measured with a gamma counter. To avoid any unspecific iodine uptake, control cells were pre-incubated with $300 \mu \mathrm{M} \mathrm{NaClO}_{4}$ for 30 min and then treated with $\mathrm{Na}^{125} \mathrm{I}$ as described above.

For iodine efflux assay, cells $\left(4 \times 10^{4}\right)$ were seeded in 12-well plates and prepared as those in iodine uptake assay. Cells were incubated in $500 \mu \mathrm{L}$ serum-free RPMI 1640 containing $1 \mu \mathrm{Ci}$ of $\mathrm{Na}^{125} \mathrm{I}$ at $37^{\circ} \mathrm{C}$ for $1 \mathrm{~h}$. Cells were washed twice with PBS, and then $500 \mu \mathrm{L}$ serum-free RPMI 1640 was added per well. The serum-free RPMI 1640 was replaced every $5 \mathrm{~min}$ for $30 \mathrm{~min}$ and the radioactivity of ${ }^{125} \mathrm{I}$ in the collected medium was measured with a gamma counter. After the last time point, trapped ${ }^{125} \mathrm{I}$ was measured. Total radioactivity at the beginning of the efflux study (100\%) was calculated by summing radioactivity of collected medium at different time point and final radioactivity of cells.

\section{In vitro clonogenic assay}

Cells $\left(4 \times 10^{2}\right)$ were seeded into 6 -well plates and left $48 \mathrm{~h}$ to attach. $48 \mathrm{~h}$ after treatment with targeted drugs, a clonogenic assay was performed. Briefly, drugcontaining medium was discarded and cells were washed twice in PBS; the medium was then replaced with $1 \mathrm{~mL}$ of regular culture medium in the presence or absence of $20 \mu \mathrm{Ci} \mathrm{Na}{ }^{131} \mathrm{I}$ for $6 \mathrm{~h}$. At the end of the treatment the radioactive medium was discarded, and cells were incubated in regular culture medium for 7 days. Finally, cells were fixed in methanol and stained with crystal violet and the number of macroscopic colonies was counted [35].

\section{Statistical analysis}

All the experiments were similarly done at least three times. The cell cycle assay data were compared using the chi square test. The data from the RT-PCR assay, radioiodine uptake and efflux assay were compared using the independent-samples $t$ test. All statistical analyses were performed using a statistical software program (SPSS, version 17.0; SPSS, Inc. Chicago, IL, USA). Significance was defined as $P<0.05$.

\section{ACKNOWLEDGMENTS}

The authors are grateful to Dr. Weibin Wang from Zhejiang University School of Medicine for helpful discussion.

\section{CONFLICTS OF INTEREST}

None of the authors has any conflict of interest to declare.

\section{GRANT SUPPORT}

This work was financially sponsored by the National Natural Science Foundation of China (81671711 and 81271609) and the Shanghai Rising-Star Program (12QH1401600).

\section{REFERENCES}

1. Kitahara CM, Sosa JA. The changing incidence of thyroid cancer. Nat Rev Endocrinol. 2016; 12:646-653.

2. Scott E, Learoyd D, Clifton-Bligh RJ. Therapeutic options in papillary thyroid carcinoma: current guidelines and future perspectives. Future Oncol. 2016; 12:2603-2613.

3. Kim S, Chung JK, Min HS, Kang JH, Park DJ, Jeong JM, Lee DS, Park SH, Cho BY, Lee S, Lee MC. Expression patterns of glucose transporter-1 gene and thyroid specific genes in human papillary thyroid carcinoma. Nucl Med Mol Imaging. 2014; 48:91-97.

4. Vaisman F, Carvalho DP, Vaisman M. A new appraisal of iodine refractory thyroid cancer. Endocr Relat Cancer. 2015; 22:R301-310. 
5. Grabellus F, Nagarajah J, Bockisch A, Schmid KW, Sheu SY. Glucose transporter 1 expression, tumor proliferation, and iodine/glucose uptake in thyroid cancer with emphasis on poorly differentiated thyroid carcinoma. Clin Nucl Med. 2012; 37:121-127.

6. Ruan M, Liu M, Dong Q, Chen L. Iodide- and glucosehandling gene expression regulated by sorafenib or cabozantinib in papillary thyroid cancer. J Clin Endocrinol Metab. 2015; 100:1771-1779.

7. Hou P, Bojdani E, Xing M. Induction of thyroid gene expression and radioiodine uptake in thyroid cancer cells by targeting major signaling pathways. J Clin Endocrinol Metab. 2010; 95:820-828.

8. Chakravarty D, Santos E, Ryder M, Knauf JA, Liao XH, West BL, Bollag G, Kolesnick R, Thin TH, Rosen N, Zanzonico P, Larson SM, Refetoff S, et al. Small-molecule MAPK inhibitors restore radioiodine incorporation in mouse thyroid cancers with conditional BRAF activation. J Clin Invest. 2011; 121:4700-4711.

9. Ho AL, Grewal RK, Leboeuf R, Sherman EJ, Pfister DG, Deandreis D, Pentlow KS, Zanzonico PB, Haque S, Gavane S, Ghossein RA, Ricarte-Filho JC, Dominguez JM, et al. Selumetinib-enhanced radioiodine uptake in advanced thyroid cancer. N Engl J Med.2013; 368:623-632.

10. Rothenberg SM, Daniels GH, Wirth LJ. Redifferentiation of Iodine-Refractory BRAF V600E-Mutant Metastatic Papillary Thyroid Cancer with Dabrafenib-Response. Clin Cancer Res. 2015; 21:5640-5641.

11. Bible KC, Ryder M. Evolving molecularly targeted therapies for advanced-stage thyroid cancers. Nat Rev Clin Oncol. 2016; 13:403-416.

12. Lee Y, Ma J, Lyu H, Huang J, Kim A, Liu B. Role of erbB3 receptors in cancer therapeutic resistance. Acta biochimica et biophysica Sinica. 2014; 46:190-198.

13. Ma J, Lyu H, Huang J, Liu B. Targeting of erbB3 receptor to overcome resistance in cancer treatment. Mol Cancer. 2014; 13:105.

14. Fattore L, Marra E, Pisanu ME, Noto A, de Vitis C, Belleudi F, Aurisicchio L, Mancini R, Torrisi MR, Ascierto PA, Ciliberto G. Activation of an early feedback survival loop involving phospho-ErbB3 is a general response of melanoma cells to RAF/MEK inhibition and is abrogated by anti-ErbB3 antibodies. J Transl Med. 2013; 11:180.

15. Montero-Conde C, Ruiz-Llorente S, Dominguez JM, Knauf JA, Viale A, Sherman EJ, Ryder M, Ghossein RA, Rosen N, Fagin JA. Relief of feedback inhibition of HER3 transcription by RAF, MEK inhibitors attenuates their antitumor effects in BRAF-mutant thyroid carcinomas. Cancer Discov. 2013; 3:520-533.

16. Cabanillas ME, Patel A, Danysh BP, Dadu R, Kopetz S, Falchook G. BRAF inhibitors: experience in thyroid cancer and general review of toxicity. Horm Cancer. 2015; 6:21-36.

17. Dadu R, Devine C, Hernandez M, Waguespack SG, Busaidy NL, Hu MI, Jimenez C, Habra MA, Sellin RV, Ying AK, Cote GJ, Sherman SI, Cabanillas ME. Role of salvage targeted therapy in differentiated thyroid cancer patients who failed first-line sorafenib. J Clin Endocrinol Metab. 2014; 99:2086-2094.

18. Thomas L, Lai SY, Dong W, Feng L, Dadu R, Regone RM, Cabanillas ME. Sorafenib in metastatic thyroid cancer: a systematic review. Oncologist. 2014; 19:251-258.

19. Medina PJ, Goodin S. Lapatinib: a dual inhibitor of human epidermal growth factor receptor tyrosine kinases. Clin Ther. 2008; 30:1426-1447.

20. Nilsson M. Iodide handling by the thyroid epithelial cell. Exp Clin Endocrinol Diabetes. 2001; 109:13-17.

21. Pesce L, Bizhanova A, Caraballo JC, Westphal W, Butti ML, Comellas A, Kopp P. TSH regulates pendrin membrane abundance and enhances iodide efflux in thyroid cells. Endocrinology. 2012; 153:512-521.

22. Rodriguez AM, Perron B, Lacroix L, Caillou B, Leblanc G, Schlumberger M, Bidart JM, Pourcher T. Identification and characterization of a putative human iodide transporter located at the apical membrane of thyrocytes. J Clin Endocrinol Metab. 2002; 87:3500-3503.

23. van den Hove MF, Croizet-Berger K, Jouret F, Guggino SE, Guggino WB, Devuyst O, Courtoy PJ. The loss of the chloride channel, ClC-5, delays apical iodide efflux and induces a euthyroid goiter in the mouse thyroid gland. Endocrinology. 2006; 147:1287-1296.

24. Silveira JC, Kopp PA. Pendrin and anoctamin as mediators of apical iodide efflux in thyroid cells. Curr Opin Endocrinol Diabetes Obes. 2015; 22:374-380.

25. Fong P. Thyroid iodide efflux: a team effort? J Physiol. 2011; 589:5929-5939.

26. Porra V, Ferraro-Peyret C, Durand C, Selmi-Ruby S, Giroud H, Berger-Dutrieux N, Decaussin M, Peix JL, Bournaud C, Orgiazzi J, Borson-Chazot F, Dante R, Rousset B. Silencing of the tumor suppressor gene SLC5A8 is associated with BRAF mutations in classical papillary thyroid carcinomas. J Clin Endocrinol Metab. 2005; 90:3028-3035.

27. Zane M, Agostini M, Enzo MV, Casal Ide E, Del Bianco P, Torresan F, Merante Boschin I, Pennelli G, Saccani A, Rubello D, Nitti D, Pelizzo MR. Circulating cell-free DNA, SLC5A8 and SLC26A4 hypermethylation, BRAF(V600E): A non-invasive tool panel for early detection of thyroid cancer. Biomed Pharmacother. 2013; 67:723-730.

28. Matsuzu K, Segade F, Matsuzu U, Carter A, Bowden DW, Perrier ND. Differential expression of glucose transporters in normal and pathologic thyroid tissue. Thyroid. 2004; 14:806-812.

29. Xing J, Liu R, Xing M, Trink B. The BRAFT1799A mutation confers sensitivity of thyroid cancer cells to the BRAFV600E inhibitor PLX4032 (RG7204). Biochem Biophys Res Commun. 2011; 404:958-962.

30. Salerno P, De Falco V, Tamburrino A, Nappi TC, Vecchio G, Schweppe RE, Bollag G, Santoro M, Salvatore G. Cytostatic activity of adenosine triphosphate-competitive kinase inhibitors in BRAF mutant thyroid carcinoma cells. J Clin Endocrinol Metab. 2010; 95:450-455. 
31. Hatzivassiliou G, Song K, Yen I, Brandhuber BJ, Anderson DJ, Alvarado R, Ludlam MJ, Stokoe D, Gloor SL, Vigers G, Morales T, Aliagas I, Liu B, et al. RAF inhibitors prime wild-type RAF to activate the MAPK pathway and enhance growth. Nature. 2010; 464:431-435.

32. Manfredi GI, Dicitore A, Gaudenzi G, Caraglia M, Persani L, Vitale G. PI3K/Akt/mTOR signaling in medullary thyroid cancer: a promising molecular target for cancer therapy. Endocrine. 2015; 48:363-370.

33. de Souza EC, Padron AS, Braga WM, de Andrade BM, Vaisman M, Nasciutti LE, Ferreira AC and de Carvalho DP. MTOR downregulates iodide uptake in thyrocytes. J Endocrinol. 2010; 206:113-120.
34. Long GV, Stroyakovskiy D, Gogas H, Levchenko E, de Braud F, Larkin J, Garbe C, Jouary T, Hauschild A, Grob JJ, Chiarion Sileni V, Lebbe C, Mandalà M, et al. Combined BRAF, MEK inhibition versus BRAF inhibition alone in melanoma. N Engl J Med. 2014; 371:1877-88.

35. Chen L, Altmann A, Mier W, Eskerski H, Leotta K, Guo L, Zhu R, Haberkorn U. Radioiodine therapy of hepatoma using targeted transfer of the human sodium/iodide symporter gene. J Nucl Med. 2006; 47:854-862. 